\section{RESPONSABILIDADE CIVIL DO ESTADO}

\section{José Salgado Martins} A responsabilidade civil do Estado pode ter origem em um dêstes
motivos: ou na culpa do funcionário ou agente do servico público ministrado pelo Estado; ples relação de causalidade objetiva entro um contrato; ou na simrepresentante do Estado e objetiva entre a prática de um ato pelo camente protegido,

Nosso intento é focalizar a matéria delicada e complexa da res-
ponsabilidade civil à

A responsabilidade divil é dos os problemas, relăções e aspectos da da intimamente ligado a tocomportamento do homem nas múltipla vida social. Ela diz com o seus semelhantes, desde nas múltiplas e multifárias relações com os puramente subjetivo que se desdobrabilidade moral que é um conceito um e cujas sancốes que se desdobra no âmago da consciência de cada ponsabilidade jurídica que tram na própria consciência, até a restivo e duas faces fundame passa a ter um prevalente aspecto objesabilidade civil.
sundamentais: a responsabilidade penal e a respon-

cia de um prejuízo, de urídica pressupõe necessàriamente a existênperturbam a ordem de uma lesão de direito. Mas os prejuízos que Ora, o dano causado pocial podem ser de natureza muito diferente. dem muito geral, repercutem sôbre tôda a reflete em interêsse de orcarácter predominantemente privado, tôda a sociedade; ora, assume um mediatamente, neflita, indireta ou

Cumpre à esfera do interêsse público.

causem um dano, isto é, ameacam os contra todos os fatos que the sôbre a qual ela está é, ameaçam os efetivaemnte lesionam a ordem

Para impedir

novo ato prejudicial, para evitar que terceiros que volte a praticar tá-lo e para ressarcir, para evitar que terceiros sejam tentados a imido Estado pune o transgressor, possível, o dano, a sociedade através pessoal ou às sanções de natureza patrimdo-o às sanções de natureza

A distinçã

e da responsabilidade civil, em conceitos da responsabilidade penal
Revista da Faculdade de Direito de Pôrto Alegre

entre o Direito Penal e o Direito Civil. Enquanto a responsabilidade penal, mercê do carácter punitivo de que não se pôde ainda desprender, assume cada vez mais um sentido subjetivo, a responsabilidade civil se estende extraordinàriamente, independizando-se do fundamento súbjetivo da culpa, para decorrer do simples risco produtor do prejuízo causado. "Admitida como base da responsabilidade civil a necessidade ou conveniência de restabelecer o estado anterior ao dano, tem-se, em conseqüência, que ao seu mecanismo não é indispensável que seja culposo o fato de que haja decorrido o prejuízo.

"Precisemos: o fundamento primário da responsabilidade civil é o princípio da restituição, isto é, a contemplação da manutenção do equilíbrio social que se afere de acôrdo com a ordem jurídico-política vigente.

"E êsse o sentido em que deve ser entendida a responsabilidade civil do Estado. Vem ela a ser, pois, a obrigação, a cargo do poder público, de reparar o dano por êle causado, restabelecendo, por meio de indenização adequada, o equilíbrio econômico rompido pelo prejuízo.

"Observação preliminar de profundo interêsse está em que a responsabilidade civil do Estado é instituto cuja compreensão se fixa marcadamente em função do regime político. É conseqüentemente na própria evolução dêste que se encontra o desenvolvimento daquele.

"Assim a irresponsabilidade do Estado perante o particular era um direito aceito no regime absolutista; a responsabilidade com base no conceito da culpa, expressão das idéias individualistas, e sua noção atual, inspirada na doutrina do risco administrativo, resultado das idéias solidaristas que dominam as modernas formas do govêrno democrático". $\left({ }^{1}\right)$

No nosso Direito essa evolução, como ainda mostra o ilustre autor citado, também se operou. Da noção civilística da responsabilidade do Estado, expressa pelo art. 15 do Código Civil, que transpunha para o âmbito da Administração as noções de culpa in eligendo e in vigilando do preponente por atos do preposto, evoluiu-se, aos poucos, para a noção moderna da responsabilidade civil do Estado, informada pela teoria do risco, cuja elaboração doutrinária se operou também no Direito brasileiro. O art. 194 da atual Constituição de 1946 abandona o conceito subjetivo de responsabilidade e acolhe a teoria objetiva do risco. O eminente José Duarte que comenta e estuda a atual Constituição, à luz do elemento histórico, mostra-nos que essa, efetivamente, foi a orientação a que os constituintes de 1946 se abeberaram.

(1) José de Aguiar Dias, Resp. Civil do Eśtado, in Rer. For. vol. 115, pág. 355; Saleilles, Accidents de travail, pág. 74; Marton, Les fondements de la resp. civ. pág. 59, n. 1; A. Ernesto Salas, La resp. por los daños causados por 
Mário Masagão, discutindo uma emenda de autoria de Aliomar Baleeiro, dizia que o dispositivo do parágrafo único do artigo 194 tinha uma função a preencher, porque muita vez a Fazenda é condenada, independentemente de culpa, ou seja, em virtude do principio do risco; mas o funcionário não deve ser condenado se não tiver havido culpa sua, porque a responsabilidade do funcionário se rege por princípio diferente, como responsabilidade individual. (ㅁ)

De outro modo também não pensa o ilustre magistrado José de Aguiar Dias, o brilhante autor do notável tratado sôbre a "Responsabilidade Civil", quando afirma que, na Constituição de 1946, o abandono da doutrina subjetiva se manifesta através do artigo 194:

"As pessoas jurídicas de Direito Público Interno são civilmente responsáveis pelos danos que seus funcionários, nessa qualidade, causem a terceiros.

Parágrafo único. Caber-lhes-á ação regressiva contra os funcionários causadores do dano quando tiver havido culpa d̦êstes".

Argumenta o eminente Aguiar Dias:

"Ora se a ação regressiva só cabe quando tiver ocorrido culpa do funcionário, como claramente se vế no dispositivo, então é que foi iniludivelmente abandonada a orientação do art. 15 do Código Civil. E se não se ousar dizer que o preceito, conjugado ao da igualdade constitucional, consagra o risco administrativo, pelo menos não será possível negar que adotou a teoria da culpa do serviço.

Quando dissemos que a responsabilidade civil independe do pressuposto da culpa não quisemos eliminála como fonte da responsabilidade. É claro que para a resistência oposta por certos espíritos conservadores ao progresso das idéias, sempre soará bem caracterizar essa culpa. através da falta dos funcionários.

Aliás, salvo casos especiais, a responsabilidade civil do Estado, quando investigada com maior rigor, como já fizera notar o grande Pedro Lessa, decorre coincidentemente da apreciação do fato danoso sob qualquer das três. orientações já referidas.

Diga-se, de passagem, que o Estado, quando contrata. ou explora serviço industrial, não é melhor nem pior que qualquer outro contratante. O Estado, quando contrata, não tem melhores títulos que o particular, conforme disse

(2) José Duarte, A Constituiģão Brasileira de 1946, vol. 3.०, pág. 354.
Epitácio Pessôa em notável parecer. Sua responsabilidade contratual decorre, pois, de infração ao estipulado, não sendo necessário insistir sôbre o assunto. O Estado responde sempre pelo dano proveniente das relações contratuais, seja lícito ou ilícito o ato do funcionário que lhe tenha dado causa. $\left({ }^{3}\right)$

A responsabilidade civil do Estado vem, pois, se firmando em abono da teoria do risco, o que, no entanto, como é óbvio, não exclui a hipótese em que essa responsabilidade decorre de culpa efetiva do funcionário encarregado do serviço, ou de falta de provimento do Estado para que o serviço se realize normalmente, de modo a não sobrevir danos a terceiros. Mas em se tratando de dano causado por culpa dos funcionário, ao prejudicado incumbe a prova da culpa, que não se presume, cabendo ao Estado, em retorsão, o ônus de provar uma das causas liberatórias da responsabiidalde: fôrça maior, caso fortuito ou culpa exclusiva do lesado.

Na responsabilidade proveniente da falta do serviço, não é necessário cogitar da culpa pessoal do funcionário. Só na ação contra êste, movida pelo Estado, deverá ser provada a culpa do funcionário, de acôrdo com as regras consagradas pelo direito civil.

$\mathrm{Na}$ culpa administrativa, portanto, decorrendo a responsabilidade da falta anônima do serviço público e não se cogitando de culpa do funcionário, é sem utilidade a distinção entre culpa pessoal e culpa profissional, asserção que é válida também para a doutrina do risco social. No sistema em que a responsabilidade só se configura em face da culpa de determinado agente do poder público essa distinção é

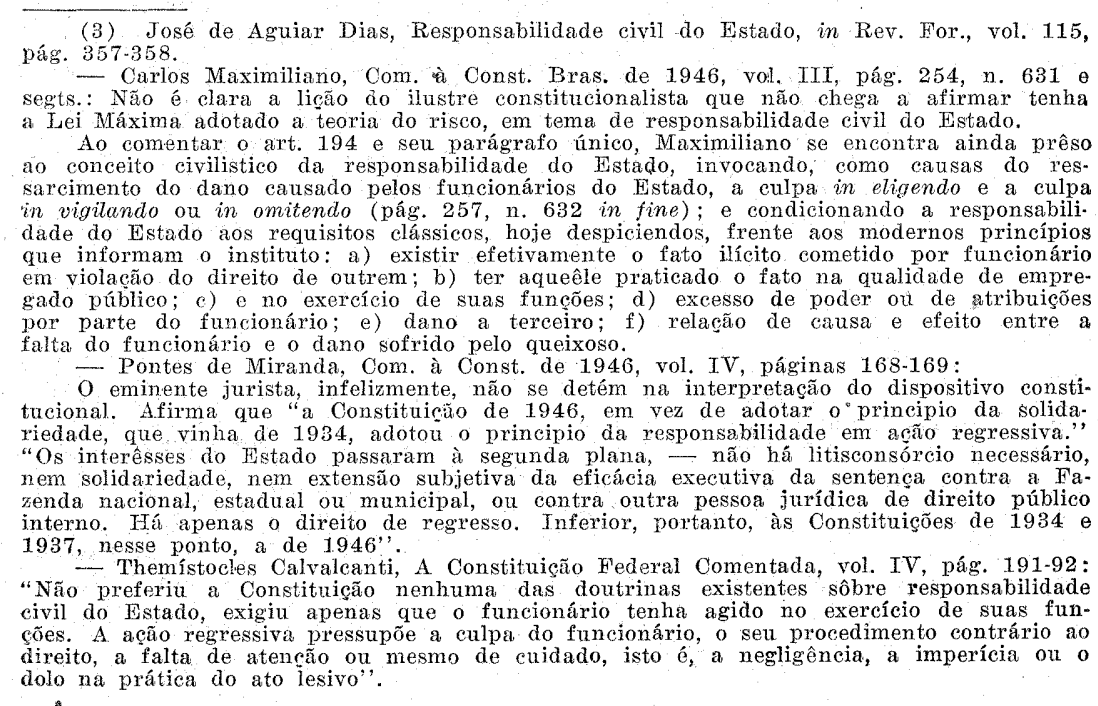


necessária porque a falta pessoal, ainda quando praticada no exercício do cargo, só empenha a responsabilidade do agente, ao passo que a falta do serviço acarreta a responsabilidade do Estado como inerente à função. (4)

De três ordens são os fatos identificáveis como faltas do serviço público, conforme resultam: de mau funcionamento do serviço, do não funcionamento do serviço, do tardio funcionamento do serviço. $\mathrm{Na}$ primeira categoria estão os atos positivos culposos da administra ção. Na segunda os fatos conseqüentes à inação administrativa quando o serviço estava obrigado a agir, embora a inércia não constitua rigorosamente uma ilegalidade. $\mathrm{Na}$ terceira as consequiências da lentidão administrativa. (Aguiar Dias).

Em brilhante e recente acórdão do Tribunal de Justiça de São Paulo, (5) está explanada com segurança a doutrina da responsabilidade civil decorrente da falta anônima do serviço público:

"A responsabilidade civil das pessoas jurídicas de Direito Público Interno está hoje regulada pela Constituição Federal, art. 194 e parágrafo único. A redação dêste parágrafo, como observou perspicazmente ilustrado juiz (Rev. dos Trib. 169/274 - 77) dá ensanchas à conclusão de que, em face do nosso Direito Positivo, a responsabilidade civil daquelas pessoas já se libertou do subjetivismo estreito para se avizinhar bastante, senão penetrar decisivamente na órbita da teoria do risco administrativo, ou pelo menos do chamado princípio da culpa administrativa ou culpa do serviço público, na qual se contêm as culpas anônimas e as exclusivas do serviço em que nenhum ato é imputável ao funcionário.

Efetivamente a cabeça do preceito constitucional já não fala, como no art. 15 do Código Civil, de procedimento contrário ao direito ou de falta a dever prescrito em lei; e o parágrafo, admitindo a ação regressiva contra os funcionários causadores do dano, somente quando

(4) Aparicio Mendez, La teoria del organo, Montevideo, 1949, pág. 56: "Eil juego de coincidencia de la voluntad técnica con la voluntad psicológica encuentra su desarrollo en la teoria de la lesponsabitad. La yuxtaposicion de añ soño ramización misma de la deston tarian los resultados sohre el Estado. Al contrario, si la voluntad psicológica se desborda (excesso de poder) o no se satisface plenamente (omisión), o se desvia con un fin ocult (desviación de poder), recae sobre el titular la obligación de reparar el dano ${ }^{2}$. tinc̃̃o feita a tetralme pelo ilustre professor uruguayo só produziŕ efeitos quanto responsabilidade do funcionário na ação que the mover o Estado. Mas para a respons bilidade dêste, perante o particular lesado, nenhum efeito produzirá a distincéco, poi subsistirá aquela jesponsabilidade, haja ou não coincidêneia, entre a vontade téenica do tiver havido culpa dêles, deixa transparecer claramente que a pessoa jurídica de direito interno responderá perante terceiros prejudicados, mesmo quando não tenha ocorrido culpa dos funcionários. Tudo leva a crer que foi adotada a teoria do risco administrativo.

Verdade é que o caso dos autos antecedeu à vigência da nova Constituição. Mas, para se inferir da responsabilidade civil da Municipalidade apelante, não há mister invocar-se a teoria do risco, pois bastará o princípio da culpa administrativa ou do serviço público que já vinha sendo recomendada e aceita pela doutrina e a jurisprudência mais categorizadas, ao influxo de opinióes mais avançadas, como a de Pedro Lessa, Amaro Calvalcante, Filadelfo Azevedo, Orozimbo Nonato, José de Aguiar Dias e outros (Cf. a obra dêste último "Da Responsabilidade Civil", vol. 2. ${ }^{\circ}$, nrs. 202, 203 e 204).

Segundo êsse prinć́pio a responsabilidade decorre da falta anônima do serviço público; não se cogita de culpa do funcionário e é sem utilidade a distinção entre culpa pessoal e culpa profissional. De três ordens são os fatos identificáveis como faltas de serviço público conforme resultem: de mau funcionamento do serviço, do não funcionamento do serviço, do tardio funcionamento do serviço".

$\mathrm{Na}$ responsabilidade civil originada pela infração de um contrato, cumpre ao Estado, como guarda e protetor do direito em geral, mostrar-se mais zeloso que o particular, na observância das cláusulas e das obrigações contratuais. As hipóteses variam extraordinàriamente em função da natureza, modalidades e nuances que podem assumir os contratos, apresentando cada hipótese certas particularidades no tocante à responsabilidade civil.

Se o contrato fôr de transporte, uma das modalidades mais comuns, a cláusula da incolumidade das pessoas é inerente ao contrato, presumindo-se a culpa do Estado ou das emprêsas transportadoras. $\mathbb{E}$ êste foi o princípio adotado pela lei n. 2.681 de 7 de dezembro de 1912, que regulou a responsabilidade civil das estradas de ferro. ( ${ }^{6}$ )

"A cláusula de incolumidade é inerente ao contrato de transporte de pessoas. Quem utiliza um meio de transporte regular celebra com o transportador uma convenção, cujo elemento essencial é a sua incolumidade, isto é, a obrigação para o transportador de levá-lo são e salvo ao lugar do destino".

(6) Eduardo Espinola, Da responsabilidade das estradas de ferro e de outras emO-Cón sap. V, "Da Tesponsabilidade civil" - Adotou o principio da culpa ex contractu. 
Henri Mazeaud e Léon Mazeaud, os eminentes autores de "Traité Théorique et Pratique de la Responsabilité Civile", estudando a cláusula de segurança pessoal nos contratos de transporte, assim es-. crevem:

"Le contrat de transport de personnes est, sans conteste, l'un de ceux pour lesquels la question de savoir s'il crée une obligation de sécurité présente les intérêts pratiques les plus considérables. Le problême se pose dans les termes suivants: Le transporteur est-il tenu, par le contrat, d'assurer la sécurité du voyageur? Par suite, en cas d'accident survenu au transporté au cours du transport, le voiturier est-il responsable contractuellement?

Bien entendu, la question ne peut se discuter que si un contrat de transport a été passé. Voici, par exemple, un voyageur qui circule en chemin de fer sans billet. Souvent, ce voyageur n'a pas voulu passer un contrat, mais simplement user frauduleusement d'un mode de transport; en cas d'accident, on ne saurait donc parler de responsabilité contractuelle de la compagnie. Ce serait cependant aller trop loin que de vouloir généraliser et dire que chaque fois qu'un voyageur monte sans billet, il n'y a pas. contrat. S'il est d'usage que le billet ne soit délivré qu'en cours de route - et il en est ainsi par exemple dans les transports en tramways et autobus - le contrat est passé dès que le voyageur pénètre dans la voiture. De même il y a contrat lorsque les agents de la compagnie laissent monter sans billet un voyageur qui n'a pas eu le temps de passer au guichet, mais qui a l'intention de payer sa place, soit en cours de route au contrôleur, soit à la gare d'arrivée.

On suppose donc un contrat de transport et un accident survenant au voyageur au cours du transport. Quelle est la nature de la responsabilité du voiturier? Peut-on dire qu'elle est contractuelle? Tout dépend de savoir si le contrat passé a mis à la charge du voiturier une obligation de sécurité relativement à la personne du transporté Que est donc le contenu du contrat? Certes, ce contrat impose des obligations qui sautent aux yeux parce qu'elles sont essentielles: le transporté a l'obligation de payer le prix; le transporteur a celle de conduire le voyageur de tel endroit à tel autre endroit, et même, bien qu'ici l'obligation soit déjá moins apparente, de le transporter dans le délai fixé par les horaires. Si donc l'une de ces obligations n'est pas remplie et qu'un dommage en résulte, si, par exemple, un préjudice est causé à un voyageur par le retard d'un train, le problème de la responsabilité se place sur le terrain contractuel. Mais n'y at-il pas d'autres obligations quí naissent du contrat? Le transporteur n'assume-t-il pas, vis-à-vis du voyageur, une obligation de sécurité?

Pendant longtemps, la jurisprudence refusa de trouver pareille obligation dans le contrat; elle affirmait que la responsabilité en cas d'accident ne pouvait être que délictuelle. Mais la Cour de cassation, suivie par toutes les juridictions, s'est ralliée, en 1911, à l'opinion contraire défendue par le procureur général Sarrut. La jurisprudence est unanime aujourd'hui à décider que le contrat de transport oblige le voiturier à assurer la sécurité du voyageur et que, par suite, la responsabilité contractuelle du transporteur peut être engagée en cas d'accident. La solution paraît raisonnable. Le voyageur entend bien que la compagnie assure sa sécurité, il exige même un certain confort, variable d'ailleurs selon la classe choisie; par exemple il veut, en hiver, être chauffé; il sera donc en droit d'intenter contre la compagnie une action en responsabilité contractuelle s'il tombe malade à la suite d'un chauffage insuffisant des voitures; à plus forte raison la responsabilité contractuelle du transporteur sera-t-elle engagée, si le voyageur est broyé dans un tamponnement. La compagnie répondra qu'il n'était pas dans son intention à elle d'assumer parcille obligation; par suite, que le contrat ne s'est pas étendu jusque-là, faute d'un accord de voluntés. Mais l'argumentation n'est pas sérieuse; au moment où elle a délivré le billet, son intention était bien qu'aucune collission ne se produise entre ses convois; ele ne prévoit l'accident que quand il s'est réalisé. C'est bien le cas de rappeler, comme le fait M. Lalou à propos de toutes les obligations de sécurité, que "les conventions obligent non seulement à ce qui y est exprimé, mais encore à toutes les suites que l'équité, l'usage ou la loi donnent à l'obligation d'après sa nature" (art. 1135 C. civ.), ce qui ne signifie point d'ailleurs que le juge puisse, au nom de l'équité, aller à l'encontre de la volonté des parties, mais que, au cas de silence des parties, il doit recourir aux règles découlant de l'équité, considérées comme l'expression de leur volonté implicite. Un lien éxiste entre l'obligation de réaliser le transport d'un voyageur et l'obligation de conduire ce voyageur en bon état, assez étroit pour que l'on puisse penser que les deux obligations n'ont pas été séparées dans la volonté des parties." ( $\left.{ }^{7}\right)$

(7) Ob. cit. pág. $166-170$, nrs. $152,153,154$ 
Não é outra a lição de Eduardo Espinola ao ensinar que a apreciação da responsabilidade do transportador entre nós sempre obedeceu ao princípio do "receptum" consagrado no édito pretoriano, princípio êste pelo qual se orientaram tôdas as legislações modernas como base das obrigações resultantes do contrato de transporte em geral, compreendendo na sua extensão atual a incolumidade da pessoa como obrigação imposta ao condutor. $\left(^{8}\right)$

Como observa o ilustre Aguiar Dias,

"A doutrina repele uma definição estreita dessa garantia, conforme a qual a obrigação do transportador se limitaria a assegurar que agiu de acôrdo com o padrão do homem prudente e diligente para estabelecer que o dever de incolumidade é obrigação determinada de não causar acidentes e não simples obrigação geral de prudência e diligência. Mazeaud et Mazeaud explicam muito bem: "O transportado pretende que o transporte não seja para êle causa de acidentes; não só exige que o transportador aja com diligência, para evitar atrasos, mas também que se empenhe em conduzir-se com prudência para evitar acidentes".

E, pois, indubitável, face à teoria do risco, adotada pela Constituição Federal vigente, que basta que se comprove a existência do contrato de transporte e que o sinistro dêle resultou. Sòmente excluirão a responsabilidade do transportador o caso fortuito, a força maior, a culpa exclusiva do passageiro.

A responsabilidade do Estado e a sua obrigação de indenizar o dano decorre, então, do inadimplemento do contrato de transporte.

O eminente professor Ruy Cirne Lima, com a segurança que caracteriza tôdas as suas lições, escreve a respeito da responsabilidade da Administração:

"A responsabilidade da pessoa administrativa fundase, nesse caso, em uma falta - não atribuível a um agente determinado, - mas à organização e funcionamento do serviço. E o que se denomina a falta do serviço.

A noção de falta do serviço implica, entretanto, certa imputabilidade do serviço público, que não é, sem dúvida, considerado pessoa distinta da Administração, mas que, sob êsse aspecto, é havido como se fôra uma pessoa. Bem é de ver-se, realmente, que a responsabilidade não

(8) Responsabilidade civil das estradas de ferro e de outras emprêsas, in Direito, decorre de um fato do serviço (como se êste fôra uma cousa), mas de uma falta do serviço (como se êste fôra uma pessoa). No caso do dano produzido pelo jôrro dágua, saído de um cano de abastecimento rompido, o fato da cousa poderia talvez atribuir-se a caso fortuito. A falta do serviço determinou, porém, a responsabilidade da administração. Exige, com efeito, a conceituação de falta do serviço que se veja, no Serviço Público, essa imanência de personalidade, tão sensível nas próprias filiais e sucursais das corporações privadas, que a sua organização especializada, de alguma forma, limita e circunscreve, dando-lhe quase expressão objetiva". ( $\left.{ }^{9}\right)$

* Como já se ressaltou, é o princípio do risco que domina atualmente a doutrina da responsabilidade civil do Estado.

Orozimbo Nonato, em brilhante conferência proferida no Instituto dos Advogados do Distrito Federal, em 27 de setembro de 1930, já acentuava o sentido moderno da teoria do risco no problema da responsabilidade. Dizia êle: "A velha noção romana e escolástica de culpa não basta mais às exigências da vida moderna e o direito deve e tem de procurar outros critérios, sem preocupações de ordem psicológica e tendentes a manter o equilíbrio das atividades e a segurança do comércio jurídico".

"As questões de culpa e de imputabilidade estão fora do quadro que deve traçar o legislador civil e, por isso, leis modernas consagram, em certos casos, um princípio digno de se generalizar a tôdas as relações civis: - deve pagar o dano o seu autor, bastando a causalidade objetiva que une o fato ao prejuízo." ( $\left.{ }^{10}\right)$

A civilização moderna, determinando relações sociais cada vez mais complexas, e sujeitando as pessoas a uma amplitude de riscos, sem paralelo em outro momento histórico, exige princípios mais eficientes para regular a indenização do dano causado pelos instrumentos que ela criou.

A fórmula civilística da responsabilidade, baseada na noção subjetiva da culpa, não corresponde às exigências dos tempos atuais.

Marton, em passagem recordada pelo brilharte A. Ernesto Salas, ressalta exemplificativamente as dificuldades de prova com que, não raro, se depara o prejudicado, que não consegue determinar a verdadeira causa do dano que sofrera e menns ainda identificar o seu autor pessoal, frente à complexidąde de fatôres concorrentes e a organização técnica dos serviços, caso em que, na expressão de Josse." rand, o acidente deve considerar-sse anônimo.

(9) Princípios de Direito Administrativo, pág. 193 dectas Brasileiras, vol. $80^{\circ}$, pág." 181 
E que a técnica mecânica e industrial moderna tem tornado cada vez mais vacilante a segurança da pessoa e mais difícil a prova da culpabilidade daquele que deu causa ao acidente. Josserand disse com muita justeza que "esta prova se torna cada vez mais difícil à medida em que $o$ acidente se realiza de maneira mais mecânica e mais anônima: seria irrisório pedir à vítima de um descarrilamento, de uma colisão de trens, de um barco a propulsão mecânica, de uma electrocução, que provasse a culpa da companhia ferroviária ou do empresário. $\mathrm{O}$ axioma tradicional - "pas de responsabilité sans faute prowvée" - terminava de fato e na maioria dos casos por suprimir tôda a responsabilidade: a regra de direito era neutralizada por sua falta de praticabilidade. $\left({ }^{11}\right)$

A transformação que se opera nesse terreno, "permite conciliar, entre o sistema da responsabilidade moral e o sistema do risco, sob o signo do bem comum, interêsses diversos que merecem consideração."

A culpa e o risco criado pela atividade humana envolvem problemas e noções que se harmonizam e se completam. A culpa envolve uma atitude moral da pessoa que, por agir com imprudência, negligência ou imperícia, se torna autora de danos e prejuízos ao direito do próximo. O risco criado, gerando também a obrigação de indenizar, se produz em conseqüência de atividade lícita da pessoa, na qual não se chega a identificar a falta ao dever de prudência e diligência a que está obrigado o homem no meio social. O conceito da culpa e do risco estão intimamente ligados ao mesmo mundo natural que cerca a pessoa. Relativamente à culpa se pressupõe que os fenômenos que se produzem como efeito da ação humana, encontram-se numa zona ao alcance da inteligência e da previsão do homem, cujas relações e leis êle conhece, podendo, de certo modo, evitar as conseqüências prejudiciais. Relativamente ao risco, em que está inteiramente ausente a noção de culpa, o evento danoso pertence ao mundo de fenômenos naturais, cuja causalidáde não foi ainda desvendada e fixada completamente pela inteligência do homem, o que impede a sua previsibilidade.

Na culpa, é o princípio moral que preside a obrigação de indenizar; na teoria do risco, são os efeitos sociais da ação que determinam o dever jurídico do ressarcimento. Através da teoria do risco, o direito protege o interêsse lícito lesado pela ação involuntária do homem, porque ao lucro que êste persegue pela atividade que o meio social proporciona, deve corresponder a obrigação de indenizar os danos causados no curso daquela atividade.

(11) Acc̉eel Ernesto Salas, La Responsabilidad por los daños causados por las cosas, Buenos Aires, 1945, pág. 23-24. Marton, Les fondements de la responsabilité civil, pás.

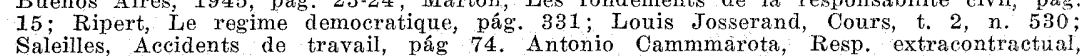
Saleilles, Accidents de travail, pág 74. Antonio Cammmarota, Resp. extracontractual,
Buenos Aires, 1947, t. 1.0, pág. 17. Louis Josserand, Evoluẹ̃o da Resp. Civil, in Rev. Buenos Aires, 1947, t. $1 .{ }^{\circ}$
Forense, vol. 86 , pág. 548 .

Revista da Faculdade de Diretto de Pôrto Alegre

A responsabilidade constitui uma espécie de ônus que se liga ao benefício da livre atividade do indivíduo. Em se tratando do Estado, mais justo é o princípio do risco, determinando a sua responsabilidade civil, porque, como realizador do direito e protetor da pessoa, deve sempre ser obrigado a indenizar os danos causados pelos seus prepostos, na atividade a que se propõe.

Como acentua Jean Dabin, (12) encarando o problema da responsabilidade civil na moral e no direito,

"C'est que les points de vue sont différents: tandis que la morale cesserait d'être elle-même si elle se désintéressait de l'élément volontaire, qui est l'élément humain par excellence, l'organisation juridique est tenue d'envisager d'abord les effets sociaux de l'action. Or l'ennemi, ici, c'est le dommage, facteur de déperdition et d'insécurité; contre ce péril, il s'agit de mener la lutte par tous les moyens préventifs et répressifs que peut suggérer l'expérience, sauf à ne pas décourager l'action utile et modérée, source de progrès. Tel est le rôle de conciliation et d'équilibre de tout système juridique de responsabilité. Étant donné la fin poursuivie, à savoir le bien commun, et puisque, dans le domainé des intérêts purement temporels, l'État est en droit d'exiger, de la part des citoyens, certains sacrifices, pareille politique est aussi légitime aux yeux de la morale la morale politique - que parfaitement conforme à la règle suprême de l'ordre juridique".

A responsabilidade pelo risco deve ser, no entanto, a exceção; e, por isso, para que ela se constitua, será necessário que a lei o tenha previsto, como decorrência do fato, como uma espécie de culpa presumida. O que hoje está na área do risco, amanhã situar-se-á na esfera da culpa. 